\title{
O Processo de Desenvolvimento de um Jogo Matemático com as Operações Básicas para Jovens com Espectro Autista
}

\author{
Anderson Daniel Stochero ${ }^{1}$, Samuel Müller Forrati ${ }^{1}$, Andréa Pereira ${ }^{1}$, Cristiane da \\ Silva Stamberg ${ }^{1}$
}

\footnotetext{
${ }^{1}$ Instituto Federal de Educação, Ciência e Tecnologia Farroupilha - IFFar (Campus Santo Ângelo) CEP: 98806-700 - Santo Ângelo - RS - Brasil

anderson stochero@yahoo.com.br, samuel.forrati@gmail.com,

\{andrea.pereira, cristiane.stamberg\} eiffarroupilha.edu.br
}

\begin{abstract}
This article presents the results of the implementation of a research project based on the proposal to create a mathematical game that covers basic operations for children with autism spectrum disorder (ASD) through the use of technological tools. The initial phase of the study was based on theoretical references and interviews with specialized people, who act in an inclusion perspective. Tests were performed with existing software aimed at identifying its positive and negative aspects for mathematical learning and thus guiding the development of the proposed game. In a perspective of inclusion, all students can be educated, where are provided educational opportunities and methods to teach them.
\end{abstract}

Resumo. Este artigo apresenta o resultado da implementação de um projeto de pesquisa, baseado na proposta de criação de um jogo matemático que abrange as operações básicas para crianças com transtorno do espectro autista (TEA), através da utilização de ferramentas tecnológicas. A fase inicial do estudo, foi a partir de referenciais teóricos e entrevistas com pessoas especializadas, que atuam em uma perspectiva de inclusão. Foram realizados testes com softwares já existentes visando identificar seus aspectos positivos e negativos, para a aprendizagem matemática e assim norteando o desenvolvimento do jogo proposto. Numa perspectiva de inclusão, defende-se que todos os alunos podem ser escolarizados, quando são proporcionadas oportunidades e métodos educacionais adequados para ensiná-los.

\section{Introdução}

A educação inclusiva busca o ingresso, acesso e permanência de quem quer que seja à educação, à escola, sem haver qualquer distinção pois o acesso de alunos com deficiência e de todos os cidadãos à educação, é um direito constitucional. A criança, ao ser diagnosticada com qualquer tipo de deficiência, têm direitos semelhantes às demais.

Ao se trabalhar com a inclusão tem-se como alternativa a inserção dos recursos digitais no ambiente escolar, podendo ser caracterizada como uma ferramenta complementar no desenvolvimento do ensino e aprendizagem. Assim, este trabalho visa apresentar as ações desenvolvidas a partir de um projeto de pesquisa que possui como proposta a utilização de ferramentas tecnológicas empregadas no processo de aprendizagem em matemática para a formação intelectual e emocional dos indivíduos.

O projeto tem como objetivo a criação de um jogo computacional capaz de possibilitar o aprendizado da matemática com significado, permitindo a inclusão e 
também a integração de crianças autistas no ambiente educacional.

\section{Contextualização}

Utilizar as tecnologias para ensinar matemática promove a colaboração entre alunos e professores na construção de novos conhecimentos. Desta forma, aliar a educação matemática com o uso das tecnologias se apresenta como uma ferramenta marcante para o ensino e aprendizagem, possibilitando ao aluno, uma proposta pedagógica que oportunize experimentar, visualizar, simular, comunicar eletronicamente e resolver problemas.

Nesse sentido, tanto a prática pedagógica quanto a matemática se modificam quando novas tecnologias tomam parte do ambiente de ensino e aprendizagem. Diante disso, professores e comunidade escolar têm dois caminhos possíveis: ignorar as tecnologias proibindo seu uso pelos alunos em sala de aula ou iniciar um processo de aprendizagem de modo a incorporar as tecnologias ao ambiente escolar [Maltempi 2008].

Macedo et. al. (2000) destacam que crianças com dificuldades de aprendizagem vão gradativamente modificando a imagem negativa do ato de conhecer, tendo uma experiência em que aprender é uma atividade interessante e desafiadora, por meio de atividades com jogos. As crianças vão ganhando autoconfiança, são incentivadas a questionar e corrigir suas ações, analisar e comparar pontos de vista, organizar e cuidar dos materiais utilizados.

É imprescindível também compreender alguns fatores relevantes sobre o Transtorno do Espectro Autista (TEA), conforme Gadia, Bordini e Portolese (2013), este espectro engloba alguns diagnósticos que variam conforme a área de menor ou maior prejuízo para o indivíduo: nas áreas da interação social, comunicação e comportamental (comportamentos restritivos, estereotipias e repetitivos).

Quanto aos recursos tecnológicos a serem utilizados, busca-se através destes agregar benefícios ao processo de ensino e aprendizagem, possibilitando, com a criação de ferramentas computacionais, atender as necessidades de alunos autistas, como por exemplo, a inclusão interfaces que levem a compreensão do porquê de cada procedimento, permitindo fomentar a capacidade de construir, de forma autônoma, o conhecimento sobre um determinado assunto [Bona 2009].

\section{Desenvolvimento}

Este estudo, sobre a utilização de ferramentas tecnológicas para o ensino e aprendizagem em matemática de crianças autistas, buscou meios possíveis de favorecer a aprendizagem auxiliando na aquisição de novas habilidades, defendendo e acreditando que a inserção do computador possa contribuir com progresso dos alunos.

O Projeto baseou-se inicialmente em referenciais bibliográficos e a submissão ao comitê de ética para aprovação. Na sequência, foram desenvolvidas as entrevistas com profissionais especializados nas áreas foco deste estudo - matemática, informática e autismo, e nesse mesmo espaço de tempo realizou-se um levantamento sobre softwares de jogos matemáticos capazes de auxiliar no processo de ensino e aprendizagem. Após o levantamento e a realização das entrevistas, ocorreu a aplicação dos softwares matemáticos pesquisados, como indica a figura 1. Esse momento contou com a participação de quatro alunos com TEA no Centro de Atenção Psicossocial Infância e 
Adolescência (CAPSI) e assim deu-se a observação comportamental dos participantes frente aos jogos apresentados.

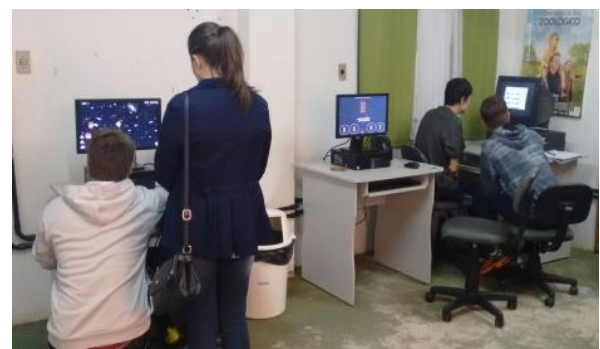

Figura 1. Aplicação de softwares matemáticos

A partir desses levantamentos, foi possível ter a perspectiva de fatores relevantes em relação aos jogos que poderiam ser implementados e quais poderiam ser descartados, identificando as necessidades de cada um, gostos e peculiaridades.

Outro ponto que merece destaque é a necessidade de significação de conceitos matemáticos, pois conforme observado, os jogos aplicados não traziam consigo a conceituação das operações matemáticas e desafios propostos. Assim, a partir das observações feitas, deu-se início a criação da primeira versão do jogo, como mostra a figura 2, que trabalharia as quatro operações básicas. De posse dessas informações foi dado início ao processo de implementação do jogo, onde foi criado um grupo de desafios de adição - para que, após testes se torne possível desenvolver os demais grupos. Para a criação das imagens foram utilizados elementos gráficos do portal livre Freepik e adaptadas para o contex to do jogo proposto utilizando ferramentas de edição gráfica como Inkscape e LibreOffice e WPS Office 2016 Free, todas livres e/ou gratuitas.

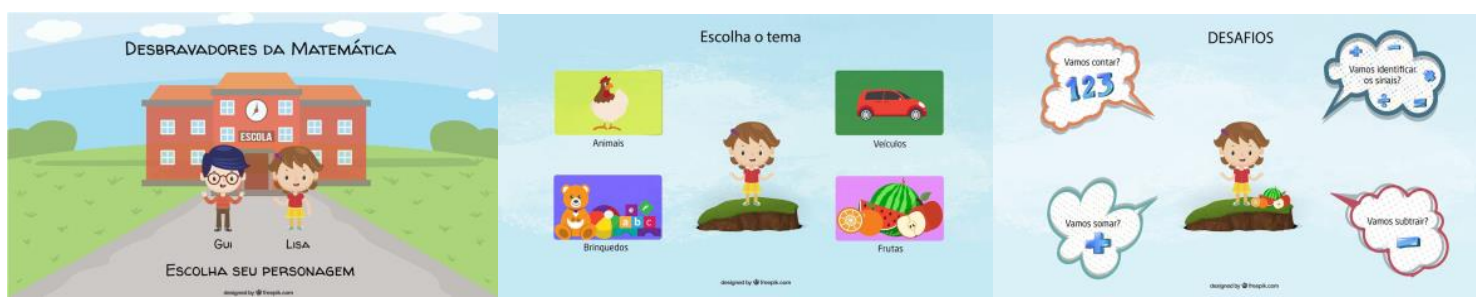

Figura 2. Tela inicial do jogo - escolha dos personagens; segunda tela: temas; terceira tela: desafios.

A primeira aplicação do jogo foi feita a um grupo de jovens com TEA, ilustrado na figura 3, onde na oportunidade, foram inseridos também materiais concretos para compreensão das operações matemáticas, com o objetivo de mostrar que as operações precisam estar sempre contextualizadas e para que os algoritmos não se tornem vazios de significado. A partir desses testes, pode-se perceber a aceitação do jogo desenvolvido, o que estimula a continuidade do projeto, visando a conclusão de todos os grupos de desafios, desta forma, podendo contribuir de forma efetiva com o processo de ensino e aprendizagem em matemática de alunos com TEA.

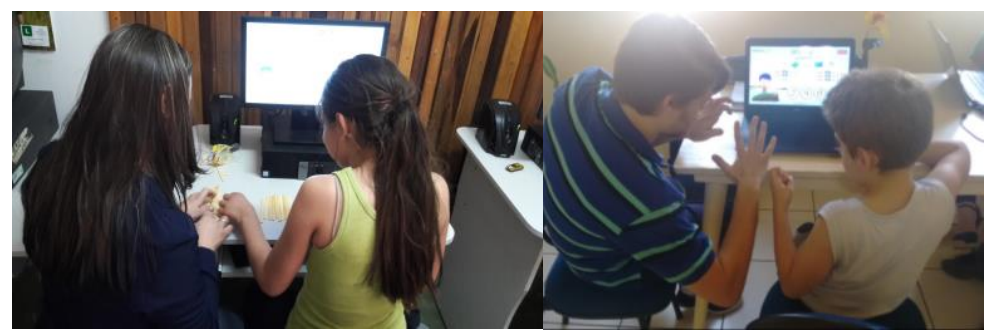




\section{Figura 3. Testes do jogo com a utilização de materiais concretos}

Na figura 4 estão expressas as telas utilizadas na aplicação do jogo, é possível visualizar a conceitualização dos dois níveis na imagem identificada pelos números 1 e 3 , além de exemplos de desafios de cada nível apresentados pelos números 2 e 4 .

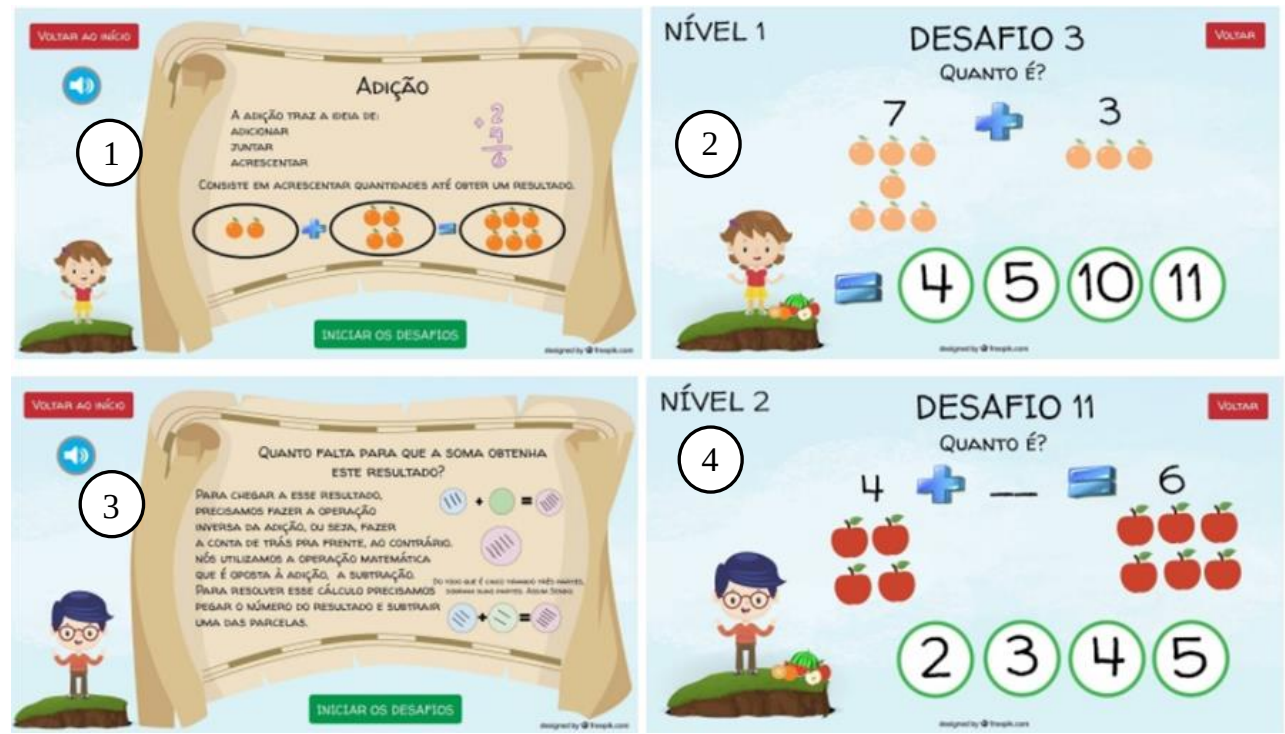

Figura 4. Telas de conceitualização $(1,3)$ e desafios $(2,4)$

\section{Considerações Finais}

Através do desenvolvimento deste estudo, buscou-se como resultado a efetiva melhoria no processo de ensino e aprendizagem em matemática, a partir da criação de um jogo computacional, tendo como foco, alunos com TEA.

Espera-se também, revelar o potencial das tecnologias no cotidiano das instituições de ensino, como um recurso pedagógico fundamental, que possa possibilitar ao aluno meios para realizar atividades com eficiência, levando em conta as experiências e atividades diárias e a contextualização do conteúdo a ser ensinado, também respeitando as necessidades e valorizando as diferenças dos alunos com autismo, comprovando que é possível a utilização dos recursos tecnológicos como ferramenta no ensino e aprendizagem da Matemática.

\section{Referências}

Bona, B. O. Análise de softwares educativos para o ensino de Matemática nos anos iniciais do ensino fundamental. Experiências em Ensino de Ciências, Carazinho, RS, v.4, p. 35-55, maio. 2009.

Gadia, C.; Bordini, D.; Portolese, J. Estratégias de Identificação. Autismo - como identificar. In: Bruni A. R. et al. Cartilha Autismo e Educação. Autismo \& Realidade, São Paulo, Brasil, p.6-23, 2013.

Macedo, L.; Petty, A. L. S.; Passos, N. C. Aprender com jogos e situações-problema. Porto Alegre: Artes Médicas Sul, 2000.

Maltempi, M. V. Educação matemática e tecnologias digitais: reflexões sobre prática e formação docente. Acta Scientiae, Canoas, v.10, n.1, p.59-67, 2008. 